\title{
CODIGESTÃO ANAERÓBIA DE DEJETOS DE SUÍNOS E NÍVEIS DE INCLUSÃO DE ÓLEO DE DESCARTE
}

Doi:http://dx.doi.org/10.1590/1809-4430-Eng.Agric.v35n4p 657-664/2015

\section{ANA C. A. ORRICO ${ }^{1}$, NATÁLIA DA S. SUNADA ${ }^{2}$, JORGE DE LUCAS JUNIOR ${ }^{3}$, MARCO A. P. ORRICO JUNIOR ${ }^{4}$, ALICE W. SCHWINGEL ${ }^{5}$}

\begin{abstract}
RESUMO: A codigestão dos dejetos de suínos e dos resíduos lipídicos vem sendo amplamente explorada, com melhorias na degradação dos substratos em digestão e, consequentemente, dos rendimentos de biogás. Assim, foram avaliados os desempenhos de biodigestores abastecidos com dejetos de suínos e crescentes níveis de óleo de descarte, por meio das produções e potenciais de produção de biogás, reduções dos teores de sólidos totais (ST), sólidos voláteis (SV) e da demanda química de oxigênio (DQO). Para o desenvolvimento do ensaio de codigestão, foram preparados substratos compostos por dejetos de suínos, óleo de descarte (nas proporções de $0 ; 2 ; 4 ; 6 ; 8 ; 10$ e $12 \%$ de óleo em relação aos teores de ST do substrato), água para diluição destes resíduos e inóculo, contendo teor inicial de $4,0 \%$ de ST e abastecimento dos biodigestores batelada. As máximas reduções de ST e SV foram de 36,8 e 41,1\% e ocorreram nos níveis de 5,2 e 5,8\% de óleo aos substratos. As inclusões de 5,4 e 6,1\% de óleo permitiram o alcance de potenciais de 222,9 e 263,6 litros de biogás por kg de ST e SV adicionados, que foram superiores em 10,8 e 5,5\% aos rendimentos observados para a dose contendo $0 \%$ de óleo. A inclusão de óleo na composição de substratos contendo dejetos de suínos nas doses entre 5 e $6 \%$ melhora os rendimentos de biogás.
\end{abstract}

PALAVRAS-CHAVE: biodigestor, suinocultura, sólidos totais, sólidos voláteis.

\section{ANAEROBIC CO-DIGESTION OF SWINE MANURE AND INCREASING LEVELS OF DISCARDED OIL}

\begin{abstract}
Swine manure and lipid residue co-digestion has been widely explored with improvements in substrate degradation, digestion and consequently biogas yield. Thus, we evaluated performance of digesters supplied with swine manure and increasing discarded oil levels, by means of potential of biogas production, and reductions of total solid content (TS), volatile solids (VS) and chemical oxygen demand (COD). To develop co-digestion tests, we prepared substrates composed by swine manure, discarded oil (with $0,2,4,6,8,10$ and $12 \%$ oil in TS substrate), water for dilution of residues and inoculum, having a initial concentration at $4 \%$ TS to supply batch-digesters. Maximum TS and VS reductions were 36.8 and $41.1 \%$ and occurred at 5.2 and $5.8 \%$ oil in substrate. Inclusions of 5.4 and $6.1 \%$ oil allowed a potential production range of 222.9 and 263.6 liters of biogas per TS and VS kilogram, which were superior in 10.8 and 5.5 to the observed yields for initial dose of $0 \%$ oil. Oil included into substrate with swine manure at doses between 5 and $6 \%$ have improved biogas yield.
\end{abstract}

KEYWORDS: digester, swine industry, total solids, volatile solids

\section{INTRODUÇÃO}

A biodigestão anaeróbia é uma técnica amplamente empregada para o tratamento e a reciclagem dos dejetos de suínos, responsáveis pela estabilização da matéria orgânica e a formação

\footnotetext{
${ }^{1}$ Zootecnista, Profa. Doutora, Faculdade de Ciências Agrárias, UFGD/Dourados - MS, Fone: (67) 3410-2373, anaorrico@ufgd.edu.br

${ }^{2}$ Med. Veterinária, Pós Doutora, Faculdade de Ciências Agrárias, UFGD/Dourados - MS, natysunada@hotmail.com

${ }^{3}$ Eng $^{\circ}$ A grônomo, Prof. Doutor, Departamento de Engenharia Agrícola, UNESP/ Jaboticabal - SP, jlu cas @ fcav.unesp.br

${ }^{4}$ Zootecnista, Prof. Doutor, Faculdade de Ciências Agrárias, UFGD/Dourados - MS, marcojunior@ufgd.edu.br

${ }^{5}$ Zootecnista, Doutoranda em Energia na A gricultura, Faculdade de Ciências Agrárias, UNESP/Botucatu, alice_watte15@hotmail.com 
de metano e dióxido de carbono como componentes principais do biogás. Os rendimentos de biogás a partir da digestão anaeróbia podem variar, principalmente em função da qualidade do resíduo adicionado ao biodigestor, do grau de diluição e do tempo de retenção (XAVIER \& LUCAS JR., 2010). No entanto, outros fatores também podem contribuir para oscilações nestes rendimentos, como a adição de um substrato que complemente a composição do dejeto (HIDALGO \& MARTIN-MARROQUÍN, 2014).

A digestão conjunta, ou codigestão dos dejetos originados com a produção animal e resíduos agroindustriais é uma técnica atual, que segundo MATA-ALVAREZ et al. (2014) vem sendo explorada intensamente devido às características individuais destes resíduos e à melhoria que ocorre quando em as sociação. Neste estudo, os autores atribuem as limitações dos dejetos a sua baixa carga orgânica e a elevados teores de $\mathrm{N}$ amoniacal, sobretudo para os de origem suína, enquanto ressaltam como fatores limitantes, para os resíduos lipídicos, a elevada taxa orgânica, que, dependendo de sua biodegradabilidade, será capaz de gerar grandes quantidades de ácidos graxos em um curto período de degradação, além de baixos teores de N. Entre os benefícios da codigestão dos dejetos suínos e dos resíduos lipídicos, segundo os autores, ainda poderiam ser ressaltados a adequação do poder tampão e o ajuste das concentrações de $\mathrm{N}$ amoniacal, que seria o suficiente para atender ao crescimento microbiano sem comprometer a formação de biogás (CHENXI et al., 2011).

Os rendimentos de biogás a partir dos dejetos de suínos, quando digeridos isoladamente, podem alcançar produções de até 684 litros de biogás por kg de sólido volátil (SV) adicionado, em um período de retenção igual a 30 dias, conforme dados de ORRICO JÚNIOR et al. (2010). No entanto, quando o óleo passa a fazer parte da composição dos substratos, em associação com os dejetos de suínos, este potencial pode alcançar valores mínimos de 716 litros de biogás por kg de SV adicionado, em biodigestores mantidos com tempo de retenção igual a 30 dias e considerandose a adição de óleo de descarte de 0,5\% da matéria fresca (PASTOR et al., 2013).

Apesar dos efeitos benéficos da codigestão dos dejetos de suínos e de óleo sobre as produções de biogás, alguns problemas operacionais foram mencionados por CIRNE et al. (2007), como o entupimento dos digestores, dificuldade de solubilidade dos substratos e flotação da biomassa, o que poderia limitar a eficiência no processo de digestão. As condições do meio em digestão também poderão apresentar-se insatisfatórias pelo acúmulo de ácidos graxos de cadeia longa, que serão originados a partir da hidrólise dos lipídeos (LANSING et al., 2010). Assim, quanto maiores os níveis de lipídeos associados aos substratos, maiores as concentrações de ácidos graxos de cadeia longa, que podem exceder os níveis assimiláveis pelos microrganismos no meio em digestão e, assim, desenvolver um ambiente tóxico e limitante para a geração de biogás.

Este trabalho foi conduzido com o objetivo de se avaliarem o desempenho de biodigestores abastecidos com dejetos de suínos e os crescentes níveis de óleo de descarte na composição de substratos, por meio das produções e potenciais de produção de biogás, reduções dos teores de sólidos totais (ST), sólidos voláteis (SV) e da demanda química de oxigênio (DQO).

\section{MATERIAL E MÉTODOS}

O trabalho foi realizado no Laboratório de Digestão Anaeróbia do Departamento de Engenharia Rural, utilizando-se de dejetos gerados no Setor de Suinocultura do Departamento de Zootecnia, ambos pertencentes à Faculdade de Ciências Agrárias e Veterinárias, da Universidade Estadual Paulista-UNESP - Câmpus de Jaboticabal, cujas coordenadas geográficas são: 21 14 '05" $\mathrm{S} ; 48^{\circ} 17^{\prime} 09^{\prime \prime} \mathrm{W}$ e altitude média de $613,68 \mathrm{~m}$.

Os dejetos de suínos foram coletados no Setor de Suinocultura da Universidade, adotando-se como procedimento de coleta a limpeza da baia dos animais no dia anterior e a retirada das fezes e urina excretadas pelos animais até o dia seguinte, procedendo-se a raspagem do piso, sem a adição de água. Os animais estavam em fase de terminação e alimentados por dietas formuladas para atender às exigências da fase. O óleo foi obtido por doação, em pastelaria comercial, já em condições de descarte (após diversas frituras). 
Para o abastecimento dos biodigestores, os substratos foram preparados com os dejetos de suínos, óleo de descarte (nas proporções de $0 ; 2 ; 4 ; 6 ; 8 ; 10$ e 12\% de óleo em relação aos teores de ST do substrato), água para dilu ição destes resíduos e inóculo, na concentração inicial de $4 \%$ de ST. O inóculo foi preparado com os dejetos de suínos e água para diluição, na concentração inicial de 4\% de ST e sendo considerado pronto a partir de aproximadamente 90 dias de fermentação, quando atingiu concentração máxima de metano.

Para o desenvolvimento da codigestão, foram utilizados 28 biodigestores modelo batelada de bancada, que ficaram alojados em galpão com cobertura e paredes de alvenaria, protegidos do sol e das chuvas.

Os biodigestores modelo batelada (Figura 1) utilizados neste trabalho foram constituídos, basicamente, por três cilindros retos de PVC, com diâmetros de 150; 200 e $250 \mathrm{~mm}$, acoplados sobre uma placa de PVC, com 2,5 mm de espessura, e podem ser caracterizados como biodigestores de bancada, com capacidade média para 4,5 litros de substrato em fermentação, cada. Os cilindros de 150 e $250 \mathrm{~mm}$ encontram-se inseridos um no interior do outro, de tal forma que o espaço existente entre a parede externa do cilindro e a parede interna do cilindro exte rior comporta um volume de água ("selo de água"), atingindo profundidade de $500 \mathrm{~mm}$. O cilindro de volume intermediário tem uma das extremidades vedadas, conservando-se apenas uma abertura para a descarga do biogás, e está emborcado no selo de água, para propiciar condições anaeróbias e armazenar o gás produzido.

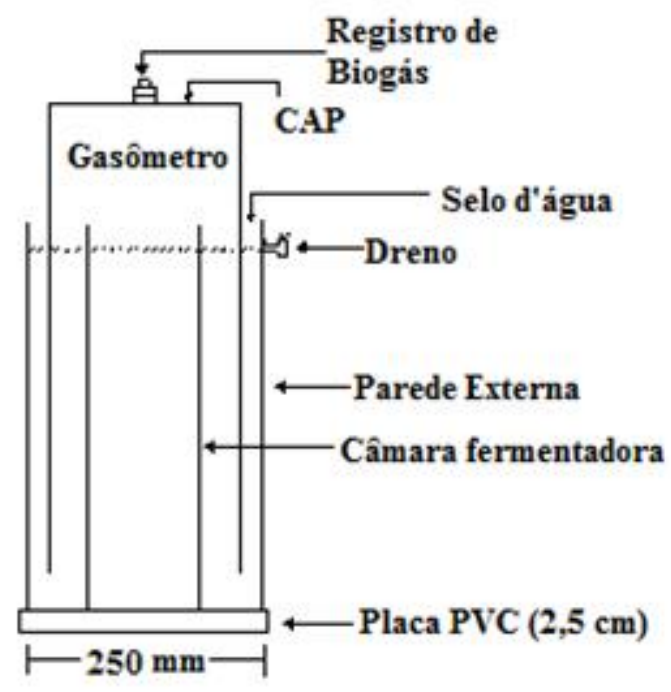

FIGURA 1. Representação esquemática de biodigestor modelo batelada de bancada. Schematic representation of tabletop batch-digester.

Nos afluentes e efluentes, foram determinadas as concentrações de sólidos totais (ST) e de sólidos voláteis (SV), a demanda química de oxigênio (DQO) e o número mais provável (NMP) de coliformes totais e termotolerantes, pela metodologia descrita por APHA (2005).

No dia do abastecimento dos biodigestores, o dejeto apresentou a seguinte composição: $28,9 \%$ de $\mathrm{ST}$, dos quais $78,3 \%$ eram voláteis, e a DQO igual a $680 \mathrm{~g} \mathrm{de} \mathrm{O}_{2} / \mathrm{kg}$ de dejeto. O inóculo continha 1,44\% de ST, sendo 67,4\% voláteis e a DQO de 293 g de $\mathrm{O}_{2} / \mathrm{L}$. Já o óleo de descarte apresentou $98 \%$ de ST e DQO igual a $2.000 \mathrm{~g}$ de $\mathrm{O}_{2} / \mathrm{L}$ de óleo. Os NMPs de coliformes totais e termotolerantes foram de $3,48 \times 10^{8}$ por 100 gramas de dejeto, e, ainda, não foram detectados coliformes no inóculo. A composição dos substratos, assim como os teores de ST contido em cada um dos componentes estão apresentados na Tabela 1. Ainda, nesta, constam os resultados que se referem à composição dos substratos submetidos à codigestão anaeróbia. Estes resultados refletem a composição semelhante dos substratos em teores de ST e SV, assim como de pH e DQO, e foram 
utilizados para os cálculos de reduções obtidas durante o processo, assim como para os potenciais de produção de biogás.

TABELA 1. Teores (em \%) de sólidos totais (ST) e quantidades (em g) de dejeto, inóculo, água e óleo para a composição de um litro de afluente, e teores de sólidos totais (ST), de sólidos voláteis $(\mathrm{SV})$ e de $\mathrm{N}$ (em \%), e demanda química de oxigênio (DQO - $\mathrm{g} \mathrm{O}_{2} / \mathrm{L}$ afluente) dos afluentes preparados com os dejetos de suínos e doses crescentes de óleo de descarte. Content (\%) of TS and quantity (g) of s wine manure, inoculum, water and oil for composition of one liter affluent, and contents of TS, VS and N (\%) and COD ( $\mathrm{g} \mathrm{O}_{2} / \mathrm{l}$ affluent) of prepared effluents with swine manure and increasing doses of discarded oil.

\begin{tabular}{|c|c|c|c|c|c|c|c|}
\hline \multirow{3}{*}{ Variáveis } & \multicolumn{7}{|c|}{ Tratamentos Experimentais (\% de óleo dos ST) } \\
\hline & 0 & 2 & 4 & 6 & 8 & 10 & 12 \\
\hline & \multicolumn{7}{|c|}{ Teores de ST\% } \\
\hline Dejeto & 28,90 & 28,90 & 28,90 & 28,90 & 28,90 & 28,90 & 28,90 \\
\hline Inóculo & 1,44 & 1,44 & 1,44 & 1,44 & 1,44 & 1,44 & 1,44 \\
\hline Óleo & 98,00 & 98,00 & 98,00 & 98,00 & 98,00 & 98,00 & 98,00 \\
\hline \multirow[t]{2}{*}{ Afluente } & 4,00 & 4,00 & 4,00 & 4,00 & 4,00 & 4,00 & 4,00 \\
\hline & \multicolumn{7}{|c|}{ Quantidade (g) para composição de um litro de afluente } \\
\hline Inóculo & 416,67 & 416,67 & 416,67 & 416,67 & 416,67 & 416,67 & 416,67 \\
\hline Óleo & 0,00 & 0,82 & 1,63 & 2,45 & 3,27 & 4,08 & 4,90 \\
\hline Dejeto & 117,65 & 114,88 & 112,11 & 109,34 & 106,57 & 103,81 & 101,04 \\
\hline \multirow[t]{2}{*}{ Água } & 465,69 & 467,64 & 469,59 & 471,54 & 473,49 & 475,45 & 477,40 \\
\hline & \multicolumn{7}{|c|}{ Composição dos substratos experimentais } \\
\hline$\overline{\mathrm{ST}}(\%)$ & 3,84 & 3,36 & 3,28 & 3,33 & 4,45 & 3,91 & 4,30 \\
\hline SV $(\%)$ & 3,06 & 2,68 & 2,63 & 2,67 & 3,33 & 2,87 & 3,25 \\
\hline $\mathrm{pH}$ & 7,07 & 7,09 & 7,05 & 7,10 & 7,11 & 7,08 & 7,03 \\
\hline $\mathrm{N}$ amoniacal (\% dos ST) & 0,82 & 0,57 & 0,43 & 0,56 & 0,65 & 0,73 & 0,69 \\
\hline DQO ( $\mathrm{g} \mathrm{O}_{2} / \mathrm{L}$ afluente $)$ & 202,10 & 202,40 & 202,70 & 203,0 & 203,40 & 203,70 & 204,00 \\
\hline
\end{tabular}

Os volumes de biogás produzidos diariamente foram determinados, medindo-se o deslocamento vertical dos gasômetros (Figura 1), e multiplicando-se pela área da seção transversal interna dos mesmos. Após cada leitura, os gasômetros foram zerados, utilizando-se do registro de descarga do biogás. Foi efetuada a correção do volume para as condições de 1 atm e $20^{\circ} \mathrm{C}$. Foram mensuradas as produções de biogás, sendo posteriormente realizados os cálculos dos potenciais de produção, dividindo-se os valores de produção pelas quantidades de litro de substrato, DQO, ST e $\mathrm{SV}$ adicionadas e reduzidas nos biodigestores.

Como delineamento experimental estatístico, utilizou-se do inteiramente casualizado, composto por 7 tratamentos (níveis de óleo de descarte) e quatro repetições (biodigestores). Os resultados foram submetidos à análise de variância, considerando-se como fonte de variação os níveis de óleo. Contrastes ortogonais foram utilizados para avaliar os efeitos de ordem linear, quadrático e cúbico dos níveis de óleo, sendo as análises realizadas pelo software SAEG versão 9.1.

\section{RESULTADOS E DISCUSSÃO}

Os valores de DQO nos afluentes diferiram (Tabela 2) e foram crescentes conforme se adicionou óleo de descarte na composição dos substratos. Este comportamento já estava previsto, pois como a inclusão do óleo foi feita em substituição aos STs adicionados pelo dejeto, restringiu-se a quantidade de dejeto adicionado em função do aumento do nível de óleo, que apresentou valor de DQO superior (2.700 g de $\mathrm{O}_{2} / \mathrm{L}$ de óleo) ao verificado no dejeto (680 g de $\mathrm{O}_{2} / \mathrm{kg}$ de dejeto). Não foi observado efeito da inclusão de óleo sobre as reduções de DQO durante a codigestão. 
Conforme o comportamento das reduções de ST e SV (Tabela 2 e Figura 2) observadas durante a codigestão dos substratos, é possível verificar que os resultados se elevaram até às doses de 5 a $6 \%$ de inclusão de óleo aos substratos, e a partir destes níveis ocorreram quedas nos valores de redução. As reduções máximas ocorreram com as inclusões de 5,19 e 5,76\% de óleo, considerando-se ST e SV, respectivamente. Estes valores indicam que, a partir destes níveis, provavelmente ocorreram condições de acúmulo de ácidos graxos de cadeia longa no meio em digestão, limitando assim a degradação do material orgânico e, consequentemente, a redução destes constituintes.

TABELA 2. Modelos de regressão, seguidos de coeficiente de determinação $\left(\mathrm{R}^{2}\right)$, probabilidade $\left(\mathrm{P}^{*}\right)$ e coeficiente de variação $(\mathrm{CV})$, para demanda química de oxigênio (DQO), reduções de sólidos totais (ST) e voláteis (SV), e potenciais de produção de biogás obtidos durante a codigestão de substratos preparados com dejetos de suínos e doses crescentes de óleo de descarte. Regression model, followed by $\mathbf{R}^{2}, \mathbf{P}^{*}$ (probability) and CV, for OCD, reductions of TS, VS and COD and biogas potentials produced during substrate co-digestion, prepared with swine manure and increasing doses of discarded oil.

\begin{tabular}{lllll}
\hline \multicolumn{1}{c}{ Parâmetro a valiado } & \multicolumn{1}{c}{ Modelo de Regres são } & \multicolumn{1}{c}{$\mathrm{R}^{2}$} & \multicolumn{1}{c}{$\mathrm{P}^{*}$} & $\mathrm{CV}$ \\
\hline DQO (g de $\left.\mathrm{O}_{2} / \mathrm{l}\right)$ no afluente & $\mathrm{y}=0,1609 \mathrm{x}+202,28$ & $0,9539<0,0001$ & 0,5 \\
Redução de DQO $(\%)$ & $\mathrm{y}=0,00857 \mathrm{x}^{2}-0,100 \mathrm{x}+96,78$ & 0,0283 & 0,1868 & 0,5 \\
Redução de ST $(\%)$ & $\mathrm{y}=-0,2265 \mathrm{x}^{2}+2,3551 \mathrm{x}+30,674$ & $0,5649<0,0001$ & 9,9 \\
Redução de SV $(\%)$ & $\mathrm{y}=-0,2016 \mathrm{x}^{2}+2,3226 \mathrm{x}+34,37$ & $0,4657<0,0001$ & 8,4 \\
L de biogás por kg de ST adicionado & $\mathrm{y}=-1,0491 \mathrm{x}^{2}+11,419 \mathrm{x}+191,86$ & $0,4444<0,0001$ & 7,5 \\
L de biogás por kg de SV adicionado & $\mathrm{y}=-1,2636 \mathrm{x}^{2}+15,378 \mathrm{x}+237,98$ & 0,3819 & 0,0005 & 7,5 \\
L de biogás por kg de DQO adicionada & $\mathrm{y}=-0,0002 \mathrm{x}^{2}+0,0028 \mathrm{x}+0,0328$ & 0,4132 & 0,0002 & 7,9 \\
Lde biogás por kg de DQO reduzida & $\mathrm{y}=-0,0002 \mathrm{x}^{2}+0,0029 \mathrm{x}+0,0339$ & 0,4321 & 0,0002 & 7,9 \\
\hline
\end{tabular}

$$
\begin{array}{cc}
y=-0,226 x^{2}+2,355 x+30,67 & y=-0,201 x^{2}+2,322 x+34,37 \\
R^{2}=0,564-S T & R^{2}=0,465-S V
\end{array}
$$

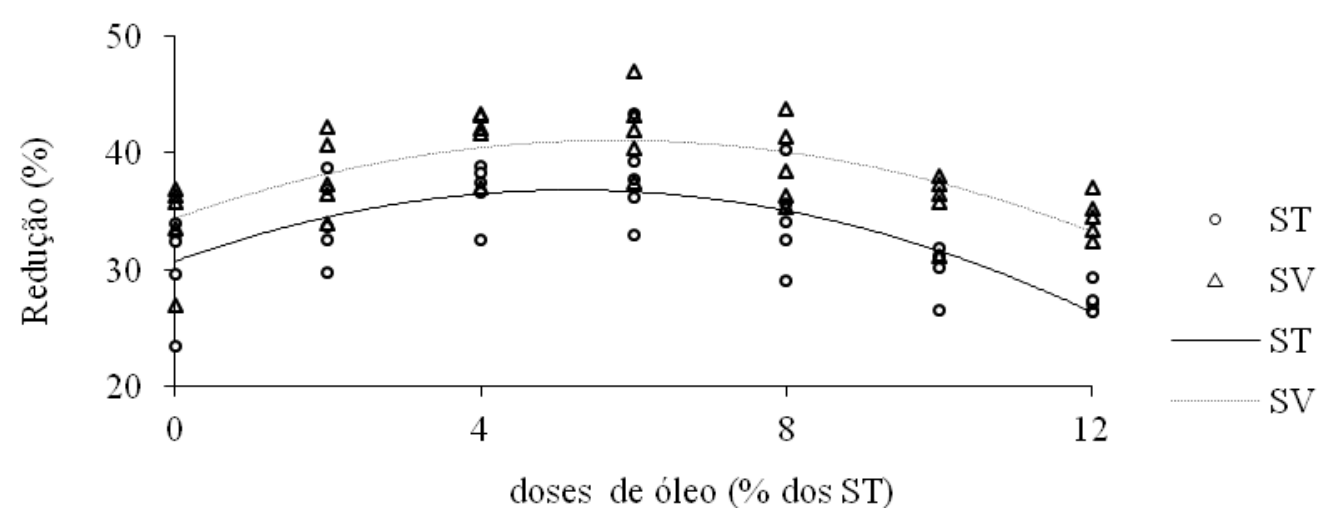

FIGURA 2. Reduções percentuais de sólidos totais (ST) e voláteis (SV) em substratos preparados com os dejetos de suínos e doses de óleo de descarte. TS and VS reductions (\%) in substrate prepared with swine manure and discarded oil doses.

Observou-se que, nas reduções de ST, para o nível ideal de inclusão de óleo de descarte $(5,19 \%)$, os valores foram 6,$71 ; 18,10$ e $25,87 \%$ superiores quando confrontados com as reduções dos níveis $8 ; 10$ e $12 \%$ de óleo, respectivamente. Já para as reduções de $\mathrm{SV}$, a superioridade do nível ideal (5,76\%), em relação às inclusões de 8; 10 e 12\% de óleo, foi de 4,88; 13,00 e 16,00\%, respectivamente. Os valores de reduções dos constituintes ST e SV $(36,81$ e 41,08\%) nos níveis ideais de inclusão de óleo superaram resultados de alguns trabalhos contendo resíduos lipídicos em codigestão com dejetos, como na pesquisa de LUSTE \& LUOSTARINEN (2010), que utilizaram subprodutos da indústria de processamento de carnes, em conjunto com dejetos, e verificaram 
reduções de SV de 38\%. Conforme destacado por RODRIGUES et al. (2014), a redução dos constituintes sólidos, sobretudo os voláteis, está relacionada com as produções de biogás, sendo que, na condição de codigestão contendo resíduos lipídicos nos substratos, estas reduções também podem refletir que não ocorreram condições inde sejáveis no meio em digestão, como acúmulo de ácidos graxos de cadeia longa e queda de $\mathrm{pH}$.

Os resultados dos potenciais de produção de biogás, considerando-se as quantidades de ST, SV e DQO adicionadas, DQO reduzida e substrato em digestão, apresentaram comportamento semelhante ao encontrado para as reduções dos ST e SVs, em que os níveis ideais de inclusão de óleo de descarte oscilaram entre 5,44 e 7,25\% (Tabela 2 e Figura 3).

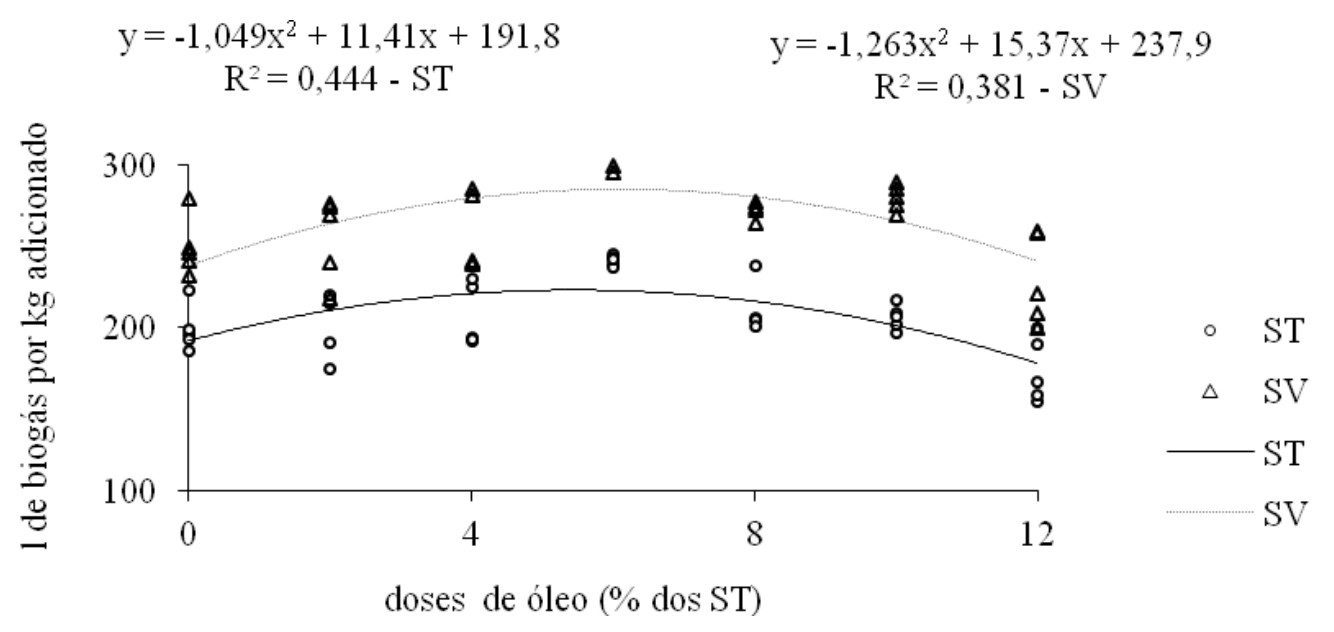

FIGURA 3. Potenciais de produção de biogás por quilograma de sólidos totais $(\mathrm{ST})$ e de voláteis (SV), adicionados em substratos preparados com os dejetos de suínos e doses de óleo de descarte. Biogas production potential per TS and VS kilogram added into substrate that are prepared with $\mathrm{s}$ wine manure and discarded oil doses.

Por meio dos níveis ideais de inclusão de óleo de descarte $(5,44 \%$ para ST e 6,08\% para SV), foi possível estimar os potenciais de produção de biogás de 222,93 L/kg ST adicionado e 263,59 $\mathrm{L} / \mathrm{kg}$ de SV adicionado. Estes valores foram 10,81 e 5,47\% superiores aos encontrados pelos biodigestores onde não se utilizou a inclusão de óleo de descarte, caracterizando assim a melhoria na digestão dos substratos quando em associação com os dejetos de suínos.

Os resultados obtidos também permitem observar que a inclusão de óleo de descarte aos substratos contendo dejetos de suínos reduziu os rendimentos de biogás quando em doses mais elevadas, provavelmente devido aos fatores já considerados anteriormente e que remetem ao acúmulo dos ácidos graxos de cadeia longa, com consequente acidificação do meio em digestão.

Utilizando a mesma fonte de óleo deste estudo, PASTOR et al. (2013) avaliaram a codigestão de resíduos urbanos (lodo de esgoto) e óleo de descarte coletado de pastelarias e obtiveram potenciais de produção de biogás de 350 até 657 litros por kg de SV adicionado, quando empregaram a dose de $0,5 \%$ de óleo em relação à massa fresca de substrato, e rendimentos de 363 até $691 \mathrm{~L} \mathrm{~kg}^{-1}$ de SV adicionado, com a dose de 1,0\% de óleo. Os potenciais obtidos por estes autores foram superiores aos gerados neste trabalho, provavelmente devido ao aquecimento dos biodigestores, mantidos com temperaturas entre 35 e $37^{\circ} \mathrm{C}$, e aos tempos de retenção, que variaram entre 10 e 30 dias.

Cabe salientar que, para as condições de desenvolvimento deste trabalho, sem aquecimento e utilizando biodigestores batelada, os rendimentos de biogás foram expressivos e refletem uma possibilidade para tratamento e reciclagem de dois resíduos que despertam sérias preocupações de contaminação ambiental, sobretudo por as doses de inclusão de óleo serem elevadas, quando comparados aos estudos realizados fora das condições brasileiras. Provavelmente, nestas cond ições, as doses de inclusão de óleo situadas entre 5 e $7 \%$ despontam como as mais promissoras, pois em 
estudo de codigestão realizado por RODRIGUES et al. (2014) foram preparados substratos contendo os dejetos de suínos e doses de óleo de descarte de pastelarias (de 8 até 20\%, com base nos STs), contando ainda com a adição de lipase e utilizando-se de biodigestores batelada mantidos em temperatura ambiente. Os autores verificaram potenciais de produção de biogás máximos de 136 e 156 litros por kg de ST e SV adicionados, concluindo que a inclusão de óleo de descarte e de enzimas nos níveis avaliados não foi benéfica.

Em um levantamento feito por LANSING et al. (2010), a partir de resultados compilados, os autores consideraram como benéfica a alcalinidade dos dejetos oriundos da prod ução animal, já que apresentam resistência para a acidificação. Os autores mencionaram também, como positiva, a adição de até $5 \%$ de óleo (em relação ao volume de substrato) em afluentes contendo dejetos de animais, resultando em ganhos de até $100 \%$ nas produções de biogás, quando comparados a substratos preparados somente com dejetos.

Os potenciais de produção de biogás por quantidades de DQO adicionadas e reduzidas indicam a dose ideal de inclusão de óleo de 7,0 e 7,3\%, gerando nestas condições valores iguais a 43 litros de biogás por kg de DQO adicionada e 44 litros por kg de DQO reduzida. Estes valores são inferiores aos potenciais esperados com base na DQO, que podem variar entre 150 e 500 litros de biogás por quantidade adicionada (MATA-ALVAREZ et al., 2014), quando avaliados substratos contendo dejetos de animais de produção e resíduos lipídicos. É possível que estes potenciais reduzidos sejam em virtude da dificuldade de aplicação da análise de DQO em substratos contendo resíduos lipídicos na composição e, assim, não reflitam diretamente os rendimentos obtidos nas condições de experimento. PASTOR et al. (2013) recomendaram que as análises de DQO não sejam parâmetros de comparação nestes estudos, pois devido à separação de fases da fração lipídica em relação à fração solúvel em água, a amostragem poderá não representar o conteúdo em digestão.

Os resultados obtidos com o desenvolvimento deste trabalho permitem o aproveitamento conjunto de resíduos com elevadas cargas orgânicas e, ainda, o emprego do óleo de descarte em concentrações acima das mencionadas como ideais por estudos realizados fora do Brasil, principalmente. Sendo assim, a codigestão dos dejetos de suínos e de óleo de descarte foi benéfica por reverter maiores produções de biogás em comparação com a digestão dos dejetos como substrato único.

\section{CONCLUSÕES}

As inclusões de óleo de descarte nas doses entre 5 e $6 \%$ dos sólidos totais na composição de substrates, em codigestão com os dejetos de suínos, melhoram os rendimentos de biogás e as reduções dos constituintes poluentes.

\section{AGRADECIMENTOS}

À Fundação de Amparo à Pesquisa do Estado de São Paulo, pela concessão da bolsa de estudos e apoio financeiro ao projeto de pesquisa.

\section{REFERÊNCIAS}

APHA - AMERICAN PUBLIC HEALTH ASSOCIATION. Standard methods for examination of water and waste water. 21 th ed. Washington: American Water Works Association, 2005. 1368 p.

CHENXI, L.; CHAMPAGNE, P.; ANDERSON, B.C. Evaluating and modeling biogas production from municipal fat, oil and grease and synthetic kitchen waste in anaerobic co-digestions.

Bioresource Technology, New York, v. 102, p. 9471-80, 2011. Disponível em: <http://ac.elscdn.com/S0960852411010546/1-s2.0-S0960852411010546-main.pdf?_tid=6e83b802-0847-11e4a476-00000aacb360\&acdnat=1405006542_e34d6b9c155e8d59c654570cdff2cfd2> Acesso em: 23 maio 2014.

CIRNE, D.G.; PALOUMET, X.; BJÖRNSSON, L.; ALVES, M. M.; MATTIASSON, B. Anaerobic digestion of lipid-rich waste - Effects of lipid concentration. Renewable Energy, Detroit, v.32, n.6, 
p.965-975, 2007. Disponível em: <http //ac.els-cdn.com/S0960148106000942/1-s2.0-

S0960148106000942-main.pdf?_tid=727de8b4-0848-11e4-9a8b-

00000aacb35e\&acdnat=1405006978_58e0d90c0bd61e6079bd1b28c41010db> Acesso em: 4 jun. 2014.

HIDALGO, D.; MARTIN-MARROQUÍN, J. M. Effects of inoculum source and co-digestion strategies on anaerobic digestion of residues generated in the treatment of waste ve getable oils.

Journal of Environmental Management, Oxford v. 142, p. 17-22, 2014. Disponível em:

<http://ac.els-cdn.com/S0301479714001844/1-s2.0-S0301479714001844-main.pdf?_tid=ff22e6fe085a-11e4-83da-00000aab0f6c\&acd nat=1405014945_1341d8e78592a654105dfe5510e955ce> Acesso em: 7 jul. 2014.

LANSING, S.; MARTIN, J. F.; BOTERO, R. B.; SILVA, T. N.; SILVA, E. D. Methane production in low-cost, unheated, plug-flow digesters treating swine manure and used cooking grease.

Bioresource Technology, New York, v.101, p.4362-4370, 2010. Disponível em: <http://ac.elscdn.com/S0960852410001860/1-s2.0-S0960852410001860-main.pdf?_tid=a4192140-0848-11e4af9f-00000aab0f6c\&acd nat=1405007061_8540aeddb89784daa7d2aa39bed7019f > Acesso em: 16 mar. 2014.

LUSTE, S.; LUOSTARINEN, S. Anaerobic co-digestion of meat-processing by-products and sewage sludge -Effect of hygienization and organic loading rate. Bioresource Technology, New York, v.101, p. 2657-64, 2010. Disponível em: <http //ac.els-cdn.com/S0960852409014473/1-s2.0-

S0960852409014473-main.pdf?_tid=b59844c4-0856-11e4-9b99-

00000aacb360\&acdnat=1405013103_d146aa79d03b5cf077847fb58a678a15> Acesso em: 2 fev. 2014.

MATA-ALVAREZ, J., DOSTA, J.; ROMERO-GÜIZA, M.S.; FONOLL, X.; PECES, M.;

ASTALS, S. A critical review on anaerobic co-digestion achievements between 2010 and 2013.

Renewable and Sustainable Energy Reviews, Amsterdam, v. 36, p. 412-27, 2014. Disponível em: <http://ac.els-cd n.com/S1364032114002664/1-s2.0-S1364032114002664-main.pdf?_tid=bb76f3200858-11e4-8012-00000aab0f26\&acdnat=1405013972_3b8f0a92c03d91dc8762d3eab63b5141>. Acesso em: 13 maio 2014.

ORRICO JÚNIOR, M.A.P.; ORRICO A.C.A.; LUCAS JÚNIOR, J. Avaliação de parâmetros da biodigestão anaeróbia de dejetos de suínos alimentados com dietas à base de milho e sorgo.

Engenharia Agrícola, Jaboticabal, v.30, n.4, p.600-607, jul./ago. 2010.

PASTOR, L.; RUIZ, L.; PASCUAL, A.; RUIZ, B. Co-digestion of used oils and urban landfill leachates with sewage sludge and the effect on the biogas production. Applied Energy,

Amsterdam, v. 107. p. 438-45, 2013. Disponível em: <http://ac.els-

cdn.com/S0306261913001736/1-s2.0-S0306261913001736- main.pdf?_tid=54c3aa18-085a-11e48012-00000aab0f26\&acd nat=1405014659_ea9ba53f803af824e33b2796b396a208> Acesso em: 1 jul. 2014.

RODRIGUES, J.P; ORRICO, A.C.A; ORRICO JUNIOR, M.A.P; SENO, L.O; ARAÚJO, L.C; SUNADA, N.S. Adição de óleo e lipase sobre a biodigestão anaeróbia de dejetos suínos. Ciência Rural, Santa Maria, v.44, n.3, p.544-547, 2014.

XAVIER, C. A. N; LUCAS JR. J. Parâmetros de dimensionamento para biodiges tores batelada operados com dejetos de vacas leiteiras com e sem uso de inóculo. Engenharia Agrícola, Jaboticabal, v.30, n.2, p.212-223, mar./abr. 2010. 